\title{
Immune-Metabolic Stress in Purulent- Inflammatory Diseases of the Skin and Soft Tissues
}

ISSN: 2637-773X

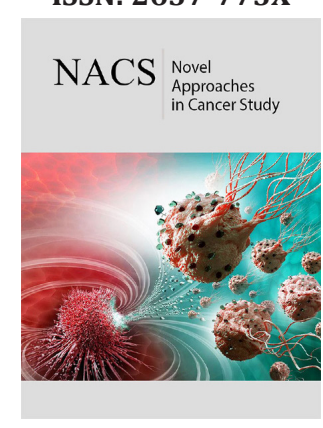

*Corresponding author: Vladimir M Zemskov, Clinical Immunology Group, AV Vishnevsky National Medical Research Center of Surgery, Moscow, Russia

Submission:

Published: November 02, 2020

Volume 5 - Issue 3

How to cite this article: Zemskov VM, Zemskov AM, Zoloedov VI, Chernitsyn II, Zemskova VA, et al. Immune-Metabolic Stress in Purulent-Inflammatory Diseases of the Skin and Soft Tissues. Nov Appro in Can Study. 5(3). NACS.000615. 2020. DOI: $10.31031 /$ NACS.2020.05.000615

Copyright@ Vladimir M Zemskov, This article is distributed under the terms of the Creative Commons Attribution 4.0 International License, which permits unrestricted use and redistribution provided that the original author and source are credited.

\author{
Zemskov VM${ }^{1 *}$, Zemskov $\mathrm{AM}^{2}$, Zoloedov $\mathrm{VI}^{2}$, Chernitsyn $\mathrm{II}^{2}$, Zemskova $\mathrm{VA}^{2}$, \\ Peleshenko EI ${ }^{2}$, NeymannV ${ }^{3}$, Pronko $\mathrm{KN}^{4}$ and Revishvili $\mathrm{ASh}^{1}$ \\ ${ }^{1}$ Clinical Immunology Group, Russia \\ ${ }^{2}$ Voronezh State Medical University, Russia \\ ${ }^{3}$ VRFD SA, Switzerland \\ ${ }^{4}$ Facecontrol Systems, Russia
}

\begin{abstract}
The article reports on a study devoted to the clinical and laboratory characteristics of the immunemetabolic stress in purulent-inflammatory diseases of the skin and soft tissues. The study included findings in 85 patients with 4 types of mono- and combined purulent-inflammatory diseases of the skin and soft tissues. Diagnostic changes were established in general indicators, detailed to the individual links of immunity, as well as the primary and secondary metabolic parameters of free radical oxidation of lipids, proteins, enzymatic and non-enzymatic mechanisms of the antioxidant system with the formalization of supporting indicators in diagnostic formulas. A direct and inverse correlation has been revealed between the key immune-metabolic indicators of patients, indicating the functional unity of the factors of immuneoxidant stress. The reference comparison group consisted of 30 single donors.
\end{abstract}

Keywords: Immune-metabolic stress; Purulent-inflammatory diseases; Skin and soft tissues; Immunologic parameters; Metabolic parameters

\section{Introduction}

It is known that metabolic processes include free radical oxidations (ROS), which provide cells with energy to prepare plastic material, participate in the metabolism of carbohydrates, lipids, proteins, nucleic acids. ROS leads to the formation of primary (diene conjugate $[\mathrm{DC}]$, ketodienes [KD]) and secondary (malonic dialdehyde [MDA], bityrozine crosslinks $[\mathrm{BC}]$, Schiff's bases [SHB]) and other products that have a positive or negative effect on the biomembrane cells. For the leveling of ROS processes in the body, an endogenous antioxidant defense system (AOD) is developed, which consists of enzymatic and non-enzymatic links. The first group includes superoxide dismutase (SOD), catalase (C), peroxidase (P), glutathion peroxidase (GP), glutathione reductase (GR); to the second, glutathione (GL), alpha-tocopherol (vitamin E, VE), plasma antioxidant activity (AOA), total thiols, non-protein thiols, protein thiols (TT, NPT, PT), etc. [1,2]. It has been established that ROS products mainly implement a suppressive and AOD - a modulating effect on the immune reactivity of patients [3]. At the same time, the direct link between immune-metabolic parameters, recognized by all authors is practically not documented [4-7].

The study aimed to validate the objective assessment of typical changes of the laboratory status using non-specific methods and to document functional relations between variations of immune and metabolic parameters (immune metabolic stress) in different forms of purulentinflammatory diseases of the skin and soft tissues.

\section{Materials and Methods}

The subject of the study were patients suffering from purulent-inflammatory diseases (PID) - deep pyoderma (DP), purulent soft tissue infection (PSTI), a combination of these diseases with skin allergies (DP+SA) or true eczema (PSTI+TE). 
All patients were divided into 4 randomized groups of 1925 people each by sex, age, disease severity. 30 healthy donors form the control group. In the acute period of the disease, routine hematological markers of inflammation were determined in patients. An immune examination identified populations and subpopulations of lymphocytes, characterized phagocyte absorbency using flow cytofluorometry (HAVIOS Beckman Coulter), using monoclonal antibodies (CYTO-STATtetraCHROM). The assessment of the oxygen-dependent metabolism of neutrophils was carried out with a nitro-blue tetrazolium test (NBT), the content of circulating immune complexes - spectrophotometrically according to Haskova with polyethylene glycol, the analysis of the immunoglobulin isotypes (IgG, IgA, IgM) was performed using the monospecific antiserum manufactured by Biosystems (Spain) by the turbidimetric method on a semiautomated biochemical analyzer Screen Master Plus (Hospitex Diagnostics S.A., Sesto Florentino, Italy) at the wavelength of $340 \mathrm{~mm}$ and cytokines enzyme-linked immunosorbent assay using "Protein Circuit" kits [3]. The parameters of ROS and AOD were determined using the methods of UV-spectrophotometry, fluorescence, reaction with 2-thiobarbituric acid, etc. [1,2].
Calculation of the coefficient of diagnostic value carried out according to the formula:

$$
K j=\frac{2 \cdot\left(\delta_{1}^{2}+\delta_{2}^{2}\right)}{\left(M_{2}-M_{1}\right)^{2}}
$$

where $\delta^{2}{ }_{1}$ and $\delta^{2}{ }_{2}$ - mean root square deviations, $\mathrm{M}_{1}, \mathrm{M}_{2}-$ mean values of the parameters of the compared groups.

The interpretation of the key laboratory tests: the greater the difference between the coefficient module and the normal level, the higher the information significance of the parameter.

Key indicators are formalized into standard immune system disorders formula (ISDF) and metabolic disorders formula (MDF). Statistical significance of correlations between metabolic and immunological parameters was characterized using correlation coefficients $>0.6[3]$.

For an integral assessment of the hematological, immune, and metabolic parameters, the ranking was used on a scale: insignificant (rank III) with a significant change in the value of the indicator in $0-33 \%$ of patients, medium (rank II) - 34-66\%, significant (rank I) - more than $66 \%[4,5]$.

\section{Result}

Table 1: The frontal matrix of statistically significant differences in laboratory parameters from the normal level in patients with deep pyoderma and purulent infection of soft tissues

\begin{tabular}{|c|c|c|c|c|}
\hline Parameters & $\begin{array}{l}\text { Deep pyoderma } \\
\text { (DP) } n=25\end{array}$ & $\begin{array}{l}\text { Purulent Soft Tissue } \\
\text { Infection (PSTI) } n=20\end{array}$ & $\begin{array}{c}\text { Deep Pyoderma }+ \text { Skin Aller- } \\
\text { gies }(\mathrm{DP}+\mathrm{SA}) \\
\mathrm{n}=19\end{array}$ & $\begin{array}{c}\text { Purulent Soft Tissue } \\
\text { Infection+ True Eczema } \\
\text { (PSTI+TE) } \\
\mathbf{n}=21\end{array}$ \\
\hline Leucocytes & + & & + & + \\
\hline Lymphocytes & + & & + & \\
\hline Stab neutrophils & & + & + & + \\
\hline Segmented neutrophils & + & + & + & + \\
\hline Eosinophils & + & + & + & + \\
\hline Monocytes & + & + & + & + \\
\hline Erythrocyte sedimentation rate (ESR) & + & & + & + \\
\hline T-cells & - & - & - & - \\
\hline T-helpers & - & - & - & - \\
\hline T-cytotoxic & - & + & + & + \\
\hline T-regulatory & - & & - & - \\
\hline T-activated & & - & & - \\
\hline $\mathrm{NK}_{\text {T-dependent }}$ & & . & + & - \\
\hline \multicolumn{5}{|l|}{$\mathrm{NK}_{\text {regulatory }}$} \\
\hline $\mathrm{NK}_{\text {cytotoxic }}$ & - & - & + & - \\
\hline B- Lymphocytes & & - & + & \\
\hline IgM & + & & + & + \\
\hline $\operatorname{IgG}$ & + & - & + & + \\
\hline
\end{tabular}




\begin{tabular}{|c|c|c|c|c|}
\hline $\operatorname{IgA}$ & & & + & + \\
\hline Circulating immune complexes (CIC) & + & + & + & + \\
\hline Medium weight molecules (MWM) & + & + & + & + \\
\hline \multicolumn{5}{|l|}{ CD11b- Lymphocytes } \\
\hline CD18- Lymphocytes & & & + & - \\
\hline Phagocytic index (PhI) & - & - & - & - \\
\hline Phagocytic number (PhN) & - & & - & - \\
\hline $\begin{array}{l}\text { Nitro blue Tetrazolium spontaneous } \\
\qquad\left(\mathrm{NBT}_{\text {spont }}\right)\end{array}$ & - & - & - & - \\
\hline $\begin{array}{l}\text { Nitro blue Tetrazolium activated } \\
\qquad\left(\mathrm{NBT}_{\text {activ }}\right)\end{array}$ & - & - & - & - \\
\hline IL-2 & & & - & - \\
\hline IL-4 & & - & - & - \\
\hline IL-6 & + & & + & + \\
\hline IL-8 & & + & + & + \\
\hline IL-10 & & + & & + \\
\hline Tumor necrosis factor (TNF) & & & + & + \\
\hline Malonic dialdehyde (MDA) & + & + & + & + \\
\hline Diene conjugates (DK) & & + & + & + \\
\hline Ketodienes (KD) & + & + & & + \\
\hline Schiff's bases (SHB) & + & + & + & + \\
\hline Bityrozine crosslinks (BC) & & & + & + \\
\hline Plasma antioxidative activity (AOA) & - & - & - & - \\
\hline Vitamin E (VE) & + & - & + & + \\
\hline Superoxide dismutase (SOD) & - & + & & + \\
\hline Ceruloplasmin (CP) & & + & - & - \\
\hline Total thiols (TT) & & - & - & - \\
\hline Non-protein thiols (NPT) & & & - & - \\
\hline Protein thiols (PT) & - & & - & \\
\hline Catalase (C) & - & - & & - \\
\hline
\end{tabular}

Notes: +/- relevantly stimulated/suppressed parameters compared to the normal level.

The frontal analysis of variation of hematologic inflammatory markers devoted to Table 1.

According to the frontal analysis of the reaction of hematological witnesses of inflammation in different nosological forms, the purulent-inflammatory diseases (PID) were stimulating in the range from 57 to $86-100 \%$, that is, not statistically significant.

At the same time, following multidirectional (stimulating/ suppressing) dynamics of immune parameters were established: with deep pyoderma (DP), the ratio (range) is $53.8 \%=-4.6 \sim+19.2$ $\%$; with purulent infection of soft tissues (PSTI) $-57.8 \%=-38.5$ $\sim+19.3 \%$; with DP+SA - $80.8 \%=-34.6 \sim+46.2 \%$; with PSTI+TE $-84.6 \%=-50.0 \sim+34.6 \%$. There is an increase in the variation of laboratory parameters in patients with a combination of purulent-inflammatory and other diseases with a predominance of depressing tendencies in all cases, with the exception of aggravation of pyoderma with skin allergies, where stimulation of parameters is the leading factor.

When considering variations from the normal level of the parameters grouped by separate links of immunity, the following changes were established. The defining dynamics of T-dependent parameters in patients with DP, PSTI, PSTI+TE was suppression in the range of $50-62.5 \%$. As in the previous, allergization of patients caused a different reaction, a parity change of index of the T-link of immunity $-37 \% \sim+37.5 \%$. At the same time, in all patients, $50-100 \%$ was activated by humoral immunity and $50-83 \%$ in phagocytic depressed. Variations in the level of interleukins were observed in the range of $16.7-33.3 \%$. 
The reactions of the metabolic immunity terms turned out to be more unambiguous (see Tables 1 and Table 2). The parameters of free radical oxidation (ROS) of substrates in patients revealed that $60-100 \%$ were stimulated, and the antioxidant system was predominantly 50-62.5\% suppressed (see Table 2). So, in patients with DP, the levels of malonic dialdehyde, ketodienes, Schiff bases were stimulated, as with PSTI and PSTI+TE, it concerned MDA, DK, KD, SHB, BC. At DP+SA it concerned MDA, DC, SHB, BC. Concerning the components of the antioxidant system in all patients, the trend of suppressing the antioxidant activity of blood plasma was predominant and less pronounced at common thiols in patients with PSTI, DP+KA, PSTI+TE. At non-protein thiols in patients with $\mathrm{DP}+\mathrm{SA}$ and PSTI+TE, but regarding catalases in patients with DP. Variations in the concentration of vitamin E, superoxide dismutase, and protein thiols were changed in different directions.

The results of a formalized assessment of immune-metabolic parameters were as follows (see Table 3).

Table 2: Parameters of the metabolic immunity in deep pyoderma and purulent infection of soft tissues.

\begin{tabular}{|c|c|c|c|c|c|}
\hline Parameters & Norm $n=30$ & $\begin{array}{l}\text { Deep Pyoder- } \\
\text { ma (DP) n=25 }\end{array}$ & $\begin{array}{l}\text { Purulent Soft } \\
\text { Tissue Infection } \\
\text { (PSTI) } n=20\end{array}$ & $\begin{array}{c}\text { Deep Pyoderma } \\
\text { +Skin Allergies } \\
(\mathrm{DP}+\mathrm{SA}) \mathrm{n}=19\end{array}$ & $\begin{array}{l}\text { Purulent Soft Tissue } \\
\text { Infection+ True Eczema } \\
\text { (PSTI+TE) } n=21\end{array}$ \\
\hline \multicolumn{6}{|c|}{ Free radical oxidation of lipids and proteins } \\
\hline Malonic dialdehyde (MDA), $\mu \mathrm{M} / \mathrm{L}$ & $1,36 \pm 0,1$ & $1,9 \pm 0,2^{*}$ & $2,5 \pm 0,11^{*}$ & $2,1 \pm 0,3^{*}$ & $2,7 \pm 0,3^{*}$ \\
\hline $\begin{array}{c}\text { Diene conjugates (DC), relative density } \\
\text { unit } / \mathrm{ml}\end{array}$ & $30,3 \pm 0,04$ & $30,5 \pm 0,1$ & $39,9 \pm 2,1^{*}$ & $32,4 \pm 0,08^{*}$ & $33,7 \pm 1,8^{*}$ \\
\hline Ketodienes «-» (KD) & $19,2 \pm 0,02$ & $20,2 \pm 0,05^{*}$ & $27,7 \pm 0,2^{*}$ & $19,5 \pm 0,8$ & $23,3 \pm 0,15^{*}$ \\
\hline Schiff's bases«-» (SHB) & $30,04 \pm 2,9$ & $40,7 \pm 7,7^{*}$ & $35,5 \pm 2,2 *$ & $36,9 \pm 4,2^{*}$ & $38,4 \pm 3,0^{*}$ \\
\hline $\begin{array}{l}\text { Bityrosine crosslinks (BC), relative } \\
\text { units } / \mathrm{ml}\end{array}$ & $0,3 \pm 0,02$ & $0,3 \pm 0,1$ & $0,35 \pm 0,6$ & $0,38 \pm 0,1^{*}$ & $0,35 \pm 0,04^{*}$ \\
\hline \multicolumn{6}{|c|}{ The antioxidant system } \\
\hline Plasma antioxidant activity (AOA), $\mu \mathrm{M} / \mathrm{L}$ & $65,3 \pm 1,3$ & $40,9 \pm 0,5^{*}$ & $30,4 \pm 1,7^{*}$ & $32,7 \pm 0,8^{*}$ & $37,7 \pm 0,7^{*}$ \\
\hline Vitamin E (VE), $\mu \mathrm{M} / \mathrm{L}$ & $20,9 \pm 3,8$ & $35,6 \pm 4,1^{*}$ & $14,9 \pm 0,5^{*}$ & $29,3 \pm 1,9^{*}$ & $26,2 \pm 3,7^{*}$ \\
\hline Superoxide dismutase (SOD), $\mu \mathrm{M} / \mathrm{L}$ & $0,9 \pm 0,03$ & $0,7 \pm 0,02^{*}$ & $1,0 \pm 0,04^{*}$ & $1,0 \pm 0,5$ & $0,5 \pm 0,15^{*}$ \\
\hline Ceruloplasmin (CP), $\mu \mathrm{M} / \mathrm{L}$ & $264,2 \pm 29,9$ & $269,5 \pm 17,3$ & $309,5 \pm 18,8^{*}$ & $220,8 \pm 25,1^{*}$ & $210,6 \pm 12,3^{*}$ \\
\hline Total thiols (TT), mM/L & $44,52 \pm 0,85$ & $38,4 \pm 6,6$ & $37,2 \pm 3,6^{*}$ & $30,2 \pm 3,3 *$ & $35,5 \pm 4,28^{*}$ \\
\hline Non-protein thiols (NPT), mM/L & $23,86 \pm 0,71$ & $25,9 \pm 1,9$ & $278 \pm 1,48$ & $22,7 \pm 0,8^{*}$ & $16,6 \pm 1,3^{*}$ \\
\hline Protein thiols (PT), mM/L & $38,8 \pm 0,82$ & $32,6 \pm 1,3^{*}$ & $40,6 \pm 0,9 *$ & $30,2 \pm 0,7^{*}$ & $37,1 \pm 0,5^{*}$ \\
\hline Catalase (C) $\mu \mathrm{M} / \mathrm{L}^{*} \min$ & $31,1 \pm 1,43$ & $28,6 \pm 1,0 *$ & $23,1 \pm 0,7^{*}$ & $29,9 \pm 1,5$ & $30,0 \pm 1,5$ \\
\hline
\end{tabular}

Notes: * significance of deviations from the norm at $\mathrm{P}<0.05$.

Table 3: Formalized rank assessment of total variations of the immune-metabolic parameters from the norm in patients with deep pyoderma and purulent soft tissue infection.

\begin{tabular}{|c|c|c|c|c|c|c|c|c|c|c|c|c|c|c|}
\hline \multirow{3}{*}{ Diseases } & \multicolumn{3}{|c|}{ Frontal Analysis } & \multicolumn{9}{|c|}{ Grouped Parameters } & \multirow{3}{*}{$\begin{array}{l}\text { Sum of } \\
\text { Ranks }\end{array}$} & \multirow{3}{*}{ Variations } \\
\hline & \multirow{2}{*}{$\Sigma$} & \multirow{2}{*}{+} & \multirow{2}{*}{-} & \multirow{2}{*}{$\mathrm{H}$} & \multirow{2}{*}{ I } & \multirow{2}{*}{ M } & \multicolumn{6}{|c|}{ Detailed values } & & \\
\hline & & & & & & & $\mathrm{C}$ & B & $\mathrm{Ph}$ & $\mathrm{Cy}$ & $\mathrm{F}$ & A & & \\
\hline 1 & 2 & 3 & 4 & 5 & 6 & 7 & 8 & 9 & 10 & 11 & 12 & 13 & 14 & 15 \\
\hline Deep pyoderma (DP) n=25 & 2 & 2 & 3 & 1 & 2 & 2 & 2 & 1 & 2 & 2 & 2 & 2 & 23 & IV \\
\hline Purulent soft tissue infection (PSTI) $n=20$ & 2 & 2 & 3 & 2 & 2 & 1 & 1 & 1 & 2 & 2 & 1 & 1 & 20 & III \\
\hline Deep pyoderma + skin allergies $(\mathrm{DP}+\mathrm{SA}) \mathrm{n}=19$ & 1 & 2 & 2 & 1 & 2 & 1 & 1 & 1 & 1 & 1 & 1 & 1 & 16 & I \\
\hline $\begin{array}{l}\text { Purulent soft tissue infection+ true eczema } \\
\text { (PSTI+TE) } n=21\end{array}$ & 1 & 2 & 3 & 1 & 1 & 1 & 1 & 1 & 2 & 1 & 1 & 1 & 15 & II \\
\hline
\end{tabular}


Notes: $\Sigma$ - sum, (+) -stimulated, (-) -suppressed parameters; $\mathrm{H}$ - hematological, I - immune, $\mathrm{M}$ - metabolic; C - cellular, $\mathrm{B}$ - B-dependent, $\mathrm{Ph}$ - phagocytic, $\mathrm{Cy}$ - cytokine, F free radical oxidation, A - antioxidant defense systemgrouped parameters; 1, 2, 3 (columns 2-13 - sufficient (1- >66\%), moderate (2- 34-66\%), insufficient (3-0-33\%) rank of variations; sum of ranks - total level of difference from normal values (15- maximum, 23- minimum); I-IV - decreasing total levels of parameter variations (Imaximum, IV- minimum).

The ranking method for evaluating the indicators revealed the maximum changes in all summarized (column 2) laboratory parameters in patients with a combination of pathological processes: PSTI+TE and DP+SA (1) and averages (2) with monopathologies: DP and PSTI. At the same time, in all cases, the general stimulation of the parameters (column 3) was moderate (2), and the suppression (column 4) was significant only in patients with PSTI+TE (2).

The reaction of hematological indicators was maximal - in DP, PSTI+TE, DP+SA (1), and medium - in PSTI (2); also immune, respectively maximal when PSTI+TE (1) and medium in DP+SA, DP, PSTI (2). The reactions of the metabolic status terms turned out to be more monotonous: significant (1) with PSTI, PSTI+TE, DP+SA; and medium (2) with DP. The detailing of the changes in immune parameters by links showed the maximum severity of variations (1) of humoral indicators (B-dependent) in all 4 variants of diseases. The prevailing T-dependent indicators of PSTI, PSTI+TE, DP+SA
(1); less pronounced (2) was cytokine (PSTI, DP), and especially phagocytic (PSTI+TE, PSTI, DP) parameters (2).

The determination of the final reducing algorithm of all significant differences in the laboratory parameters studied for individual nosoforms of purulent-inflammatory diseases was as follows: purulent soft tissue infection complicated by true eczema, deep pyoderma, aggravated by skin allergies; and monopathology, involving purulent infection of soft tissues and deep pyoderma.

The results of the determination of the signaling immune and metabolic laboratory parameters of patients with different purulent-inflammatory diseases using the coefficient of diagnostic value are presented in Table 4. According to the standard immune system disorders formula (ISDF) in patients with DP the accumulation of 3 degrees of auto-aggressive circulating immune complexes, cytotoxic natural killer cells, proinflammatory cytokine - interleukin-6 was decisive. In patients with another variant of PSTI, the leading group had the ultimate increase in the content of $\mathrm{T}$ cytotoxic lymphocytes of suppressors and proinflammatory IL-8 against the background of a decrease in the level of B-cells of moderate severity. In patients with a combined pathology, DP+SA, the leading ones turned out to be significant eosinophilia, an excess of B-cells, and proinflammatory tumor necrosis factor-alpha. In the case of purulent soft tissue infection+ true eczema, an imbalance of regulatory subpopulations is formed T-helper cells and T-cytotoxic suppressors against the background of the accumulation of CIC in blood serum, 3 degrees in all cases.

Table 4: Signaling parameters of the key of immune-metabolic disorders formulas and their correlation indicators in patients with deep pyoderma and purulent soft tissue infection.

\begin{tabular}{|c|c|c|c|}
\hline Disorder & $\begin{array}{l}\text { Immune System Disor- } \\
\text { ders Formula (ISDF) }\end{array}$ & $\begin{array}{l}\text { Metabolic Disorders } \\
\text { Formula (MDF) }\end{array}$ & Correlations \\
\hline Deep pyoderma (DP) n=25 & $\mathrm{CIC}_{3}^{+} \mathrm{NKC}_{3}^{+} \mathrm{IL6}_{3}^{+}$ & $\mathrm{VE}_{3}^{+} \mathrm{MDA}_{2}^{+} \mathrm{AOD}_{2}^{-}$ & $\begin{array}{c}\mathrm{CIC}_{3}^{+}+\mathrm{SHB},-\mathrm{CP} \\
\mathrm{NKc}_{3}^{+}+\mathrm{AOD} \\
\mathrm{IL6}_{3}^{+}+\mathrm{KD} \\
\end{array}$ \\
\hline $\begin{array}{l}\text { Purulent soft tissue infection (PSTI) } \\
\qquad \mathrm{n}=20\end{array}$ & $\mathrm{Tcyt}_{3}^{+} \mathrm{IL}^{+}{ }_{3} \mathrm{~B}_{2}^{-}$ & $\mathrm{AOD}_{3}^{-} \mathrm{KD}_{2}^{+} \mathrm{MDA}_{1}^{-}$ & $\begin{array}{l}\mathrm{Tcyt}_{3}^{+}+\mathrm{MDA} \\
\mathrm{B}_{2}^{-}+\mathrm{AOD},+\mathrm{C}\end{array}$ \\
\hline $\begin{array}{l}\text { Deep pyoderma +skin allergies (DP+- } \\
\qquad \text { SA) } n=19\end{array}$ & $\operatorname{Eos}_{3}^{+} \mathrm{B}_{3}^{+} \mathrm{TNF}_{3}^{+}$ & $\mathrm{TT}_{2}^{-} \mathrm{MDA}_{2}^{+} \mathrm{AOD}_{2}^{-}$ & $\begin{array}{c}\mathrm{Eos}_{3}^{+}+\mathrm{DK},-\mathrm{AOD} \\
\mathrm{B}_{3}^{+}+\mathrm{VE},-\mathrm{SHB} \\
\mathrm{TNF}_{3}^{+}+\mathrm{BC},-\mathrm{MDA},-\mathrm{TT}\end{array}$ \\
\hline $\begin{array}{l}\text { Purulent soft tissue infection+ true } \\
\text { eczema (PSTI+TE) } n=21\end{array}$ & $\mathrm{Th}_{3}^{-} \mathrm{Tcyt}_{3}^{+} \mathrm{CIC}_{3}^{+}$ & $\mathrm{SHB}_{2}^{+} \mathrm{SOD}_{2}^{-} \mathrm{VE}_{3}^{+}$ & $\begin{array}{c}\mathrm{Th}_{3}^{-}+\mathrm{MDA}+\mathrm{DK},-\mathrm{SOD} \\
\mathrm{Tcyt}_{3}^{+}-\mathrm{PT},-\mathrm{CP} \\
\mathrm{CIC}_{3}^{+}+\mathrm{BC},-\mathrm{AOD}\end{array}$ \\
\hline
\end{tabular}

Notes: parameters that have valid correlations are given in bold (see above), other symbols see above. The second and third columns give formulas for key indicators of the immune and metabolic systems (+ increase, - decrease in immune indicators, numerical values in formulas - the degree of change). The fourth column gives positive $(+)$ or negative $(-)$ correlation of laboratory markers.

The metabolic disorders formula (MDF) in patients with deep pyoderma included $\left(\mathrm{VE}_{3}^{+} \mathrm{MDA}_{2}^{+} \mathrm{AOD}_{2}^{-}\right)$stimulation of grade 2 levels of malonic dialdehyde, amid the imbalance of non-enzymatic ROS mechanisms of vitamin $\mathrm{E}$ and the antioxidant activity of mediumintensity blood plasma in both cases. In patients with purulent soft tissue infection, the leading $\left(\mathrm{AOD}_{3}^{-} \mathrm{KD}_{2}^{+} \mathrm{MDA}_{1}^{-}\right)$had a third-degree 
AOD reduction, an increase in ketodiene (ROS), a second degree; and a decrease in MDA (ROS), the first degree. The combination of $\mathrm{DP}+$ skin allergy $\left(\mathrm{TT}_{2}^{-} \mathrm{MDA}_{2}^{+} \mathrm{AOD}_{2}^{-}\right)$was a decrease in the concentration of total thiols, an increase of MDA, and a decrease in AOD, the average severity in all cases. In turn, the weight of PSTI with true eczema contributed $\left(\mathrm{SHB}_{2}^{+} \mathrm{SOD}_{2}^{-} \mathrm{VE}_{3}^{+}\right)$to the stimulation of the formation of ROS factor, Schiff's bases and an imbalance of the enzymatic and non-enzymatic mechanisms of the antioxidant system, superoxide dismutase (suppression) and vitamin E (stimulation) of 2-3 degrees.

The definition of strong, with a correlation coefficient of $>0.6$, reveals the functional unity of the consistent dynamics of immune and metabolic parameters in patients with different options for purulent-inflammatory diseases in the acute stage (see Table 4).

From Table 4 it follows that in patients with deep pyoderma in the acute stage, the key parameter of the immune system disorders formula (ISDF) reveals an increased concentration of circulating immune complexes was positively consistent with the Schiff's base level (the ROS system) and negatively with the AOD enzyme factor ceruloplasmin. At the same time, an overestimated amount of cytotoxic natural killer cells was directly associated with antioxidant activity (AOD) of blood plasma, and the content of interleukin 6 was also associated with ketodiene related to the processes of free radical oxidation of lipids and proteins.

In patients with purulent soft tissue infection, the dynamics of the signaling parameters were an increased number of $\mathrm{T}$ cytotoxic suppressors directly correlated with ROS factors, malonic dialdehyde, a deficiency of B-lymphocytes with non-enzymatic and enzymatic mechanisms of the antioxidant system AOD and Catalase.

Combined pathology of DP with SA caused the modification of not only the composition of typical ISDF, MDF but also the associations of their components belonging to the ROS system, various AOD mechanisms. Thus, eosinophilia was directly related to the concentration of diene conjugates and back to AOD. The accumulation of B-lymphocytes is also variable with the level of vitamin E and Schiff's bases. An excess of the proinflammatory TNF- $\alpha$ was positively associated with bitirozine crosslinks and negatively with malonic dialdehyde and common thiols.

The combination of PSTI with TE, in turn, contributed to a consistent positive dynamics of the regulatory subpopulation
T-helpers with MDA, DC, and negative with superoxide dismutase. Also, T cytotoxic suppressors were negative with protein thiols, ceruloplasmin. CIC multidirectional were tied with BC and AOD.

Thus, there are features of changes in hematological, immune, and metabolic parameters in patients suffering from various mono and combined purulent-inflammatory diseases of the skin and soft tissues with the possibility of using these data after mathematical processing for diagnostic purposes are established.

\section{Conclusion}

During the examination of more than 100 patients suffering from 4 types of mono- and combined purulent inflammatory diseases of the skin and soft tissues, diagnostic changes were established in general indicators, detailed to the individual links of immunity, as well as the primary and secondary metabolic parameters of free radical oxidation of lipids, proteins, enzymatic and non-enzymatic mechanisms of the antioxidant system with the formalization of supporting indicators in diagnostic formulas. A direct and inverse correlation has been revealed between the key immune-metabolic markers of patients, indicating the functional unity of the factors of immune-oxidant stress.

\section{References}

1. Lutsky MA, Retzky MI, Meshcheryakov MP (2001) Laboratory study of the parameters of lipid peroxidation and the system of antioxidant protection of the body: A manual. Voronezh State Technical University, Moscow, Russia, p.42.

2. Lutsky M, Zemskov A, Choporov O (2016) Immune-oxidative stress in cerebrovascular diseases. Lap Lambert Academic Deutschland, p.223.

3. Zemskov A, Esaulenko IE, Chereshnev VA, Zemskov VM, Suchkov SV, et al. (2017) A course of lectures on clinical immunophysiology. Textbook. Rhythm, Voronezh, Russia, p.1048.

4. Zemskov AM, Chereshnev VA, Revishvili ASh, Zemskov VM, Popov VI, et al. (2018A) Problems of clinical immunology of the XXI century. Edition Scientific book, Moscow, Russia, p.320.

5. Zemskov AM, Chereshnev VA, Revishvili ASh, Zemskov VM, Popov VI, et al. (2018B) Problems of clinical immunology of the XXI century. Natural and medicinal mechanisms of regulation of immunological homeostasis. Edition Scientific book, Moscow, Russia, p.286.

6. Kalinina NM, Ketlinsky SA, Okovity SV, Shulenin SN (2008) Diseases of the immune system. Diagnostics and pharmacotherapy. Eksmo, Moscow, Russia, p.494.

7. Novikov DK, Novikov PD (2009) Clinical immunopathology. Medical Literature, Russia, p.449. 